\title{
Influence of aging treatment on microstructure and mechanical properties of a new high strength TB17 titanium alloy
}

\author{
Wang Zhe ${ }^{1 \mathrm{a}}$, Wang Xinnan ${ }^{1 \mathrm{~b}}$, Shang Guoqiang ${ }^{1 \mathrm{c}}$, Zhu Liwei $^{1 \mathrm{~d}}$, Li Jing ${ }^{1 \mathrm{e}}$, Fei \\ Yue $^{1 \mathrm{f}}$, Tian Shuai ${ }^{1 \mathrm{~g}}$, Zhu Zhishou $^{1 \mathrm{~h}^{*}}$
}

Titanium Alloys Laboratory, Beijing Institute of Aeronautical Materials , Beijing 100095 , China atianchenzhe@163.com , bnansmily@126.com , cshanggq1984@126.com , dzhuliwei621@163.co

m , etjulijing@126.com , faaafeiyue@163.com , gtianshuai621@126.com , hzhuzzs@126.com

Corresponding Author : Zhu Zhishou

KEY WORDS: TB17 titanium alloy ; High strength ; Aging ; Precipitation

\begin{abstract}
Scanning Electron Microscope (SEM), Transmission Electron Microscope (TEM) and X-Ray Diffraction (XRD) were employed to investigate the influence of heat treatment conditions on microstructure and mechanical properties of a new high strength TB17 titanium alloy at aging temperature from $530^{\circ} \mathrm{C}$ to $620^{\circ} \mathrm{C}$. The results showed that the aging temperature had a significant influence on microstructures and mechanical properties of the alloy. At aging temperature of $530^{\circ} \mathrm{C}$, the existence of lamellar secondary $\alpha$ phase with a size of $40 \mathrm{~nm}$ resulted in high tensile strength above $1500 \mathrm{MPa}$ and acceptable elongation of $6 \%$. The secondary $\alpha$ phases had a great effect on the mechanical properties of TB17 titanium alloy, i.e. the fine acicular secondary $\alpha$ phase contributed to quasi-cleavage fracture, while the coarse $\alpha$ phases lead to the ductile fracture. Finer secondary $\alpha$ phase could provide more $\alpha / \beta$ phase interface, which could act as the site of micro-crack nucleation and hinder the dislocation movement inside the titanium alloy, thus, a higher strength could be obtained for the TB17 titanium alloy.
\end{abstract}

\section{Introduction}

Titanium and titanium alloys were widely used in the aerospace, biomedical defense and sporting goods industry, owing to its high specific strength-to-density ratios, good creep and corrosion resistance. The $\beta$ titanium alloys were considered to have great potentials in the aerospace fields due to its balance between strength and ductility [1-3]. In the last decades, the application of near $\beta$ titanium alloys, such as VT22, Ti-1023 and Ti-5553, are gradually increased in aerospace structural fields due to their higher strength-to-density ratios, better fatigue and crack propagation properties comparing with $\alpha+\beta$ titanium alloys [4-5]. Due to the poor ductility of $\beta$ titanium alloys above $1350 \mathrm{MPa}$, their applications in aerospace fields are hindered [6-7]. The optimization of mechanical properties is attributed to the adjustment of process parameters, holding time or rate of both the solution treatment and aging, which help to control the volume fraction size, morphology, and distribution of both the primary and secondary $\alpha$ phase. The pramary $\alpha$ phase can be formed during isothermal heat treatment below $\beta$ - transus temperature or slow cooling from the $\beta$ phase field. The secondary $\alpha$ phase formed by precipitated from the $\beta$ phase matrix. The secondary $\alpha$ phase morphology, volume fraction, size and distribution have a significiant effect on the mechanical properties of $\beta$ titanium alloy[8-10]. Thus, it is important to invest the relations between secondary $\alpha$ phase and the mechanical properties of $\beta$ titanium alloys.

Recently, a novel metastable $\beta$ titanium alloy named TB17 titanium alloy with independent intellectual property rights has been developed. This alloy has a great potential as aerospace structure material with a strength above $1400 \mathrm{MPa}$ and good strength-plasticity match (elogation above $7 \%$ ), the plane fracture toughness above $40 \mathrm{MPa} \cdot \mathrm{m}^{1 / 2}$, and high cycle fatigue can above 
$875 \mathrm{MPa}(\mathrm{R}=0.1)$ after solution and aging heat treatment. The present work not only helps to establish the quality correspondence among microstructure and strength but also contributes to the accurate control and prediction on the process conditions for the TB17 titanium alloy to obtain the desired mechanical properties.

\section{Materials and experimental procedures}

The TB17 titanium alloy was melted by multiple vacuum arc re-melted (VAR) method. The ingot with $\Phi 220 \mathrm{~mm}$ in diameter was first forged at $\beta$ phase temperature and then hot rolled at the $\alpha / \beta$ field down to $150 \mathrm{~mm}$ (width) $\times 120 \mathrm{~mm}$ (thickness) $\times$ L. The $\beta$ transition temperature of TB17 alloy is measured as $845^{\circ} \mathrm{C}$ using metallographic method. Samples from the as forged materials were firstly solution treated at $825^{\circ} \mathrm{C}$ (below $\beta$ transition temperature) for 1.5 hours in an air furnace and then followed with air cooling. Then, the sample after solution treated were undergone aging heat treatment at $530^{\circ} \mathrm{C}, 550^{\circ} \mathrm{C}, 570^{\circ} \mathrm{C}$ and $620^{\circ} \mathrm{C}$, respectively, for 8 hours and then followed with air cooling.

The conventional optical microstructure (OM), SEM and TEM were observed. The TME observation for the rolled specimen was preformed on Tecnai G2 F30S (FEI America) under an acceleration voltage of 300KV. The XRD experiment was carried on the D8 advance apparatus

(Bruker Germany) .Fig. 1 shows the micrographs of the initial microstructure for TB17 titanium alloy. The forged microstructure of the matrix consists of globular $\alpha$ phase particles.

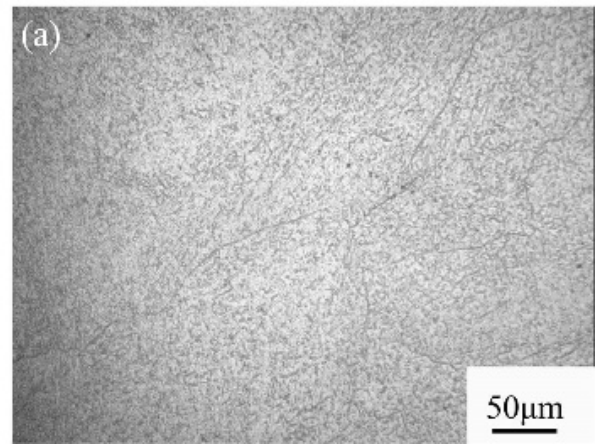

Fig.1 Micrographs of the initial microstructure for TB17 titanium alloy

\section{Results}

\subsection{Microstructure}
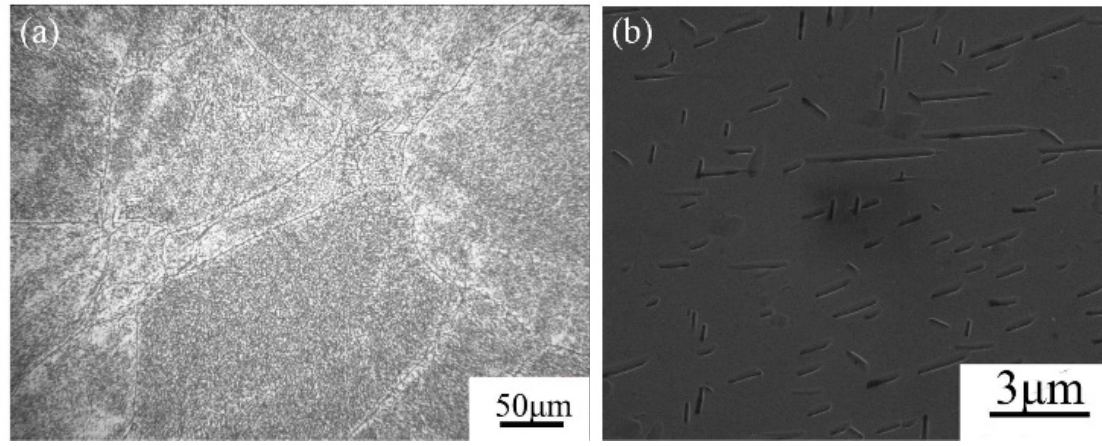

Fig.2 Micrographs of the microstructure for TB17 titanium alloy after solution treatment (a.

Optical micrograph; b. SEM micrograph) 


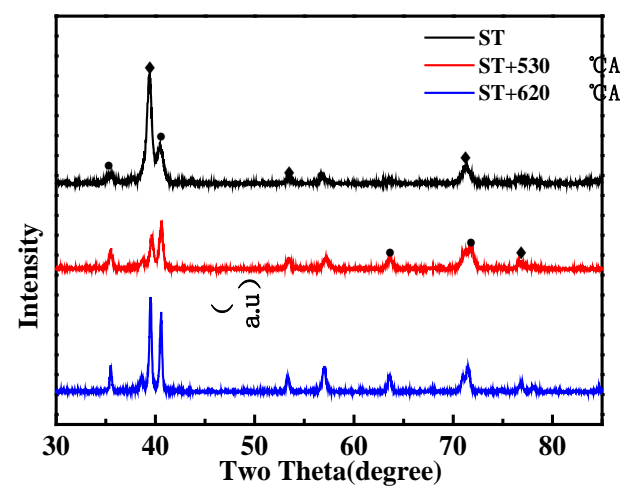

Fig.3 X-ray diffraction patterns of TB17 titanium alloy for different heat treatment

The initial microstructure of TB17 titanium alloy in a solution treatment below $\beta$ transition temperature is show in Fig.2. The result presents a large number of primary $\alpha$ phase dispersed on the $\beta$ phase matrix with a size of about $50 \mu \mathrm{m}$. Primary $\alpha$ phase is short rod like with about $0.2 \mu \mathrm{m}$ in width and length inhomorogenous. The microstructure of TB17 titanium alloy during solution treatment at $\alpha+\beta$ phase temperature only consisted by $\alpha$ phase and $\beta$ phase (Fig. 3).
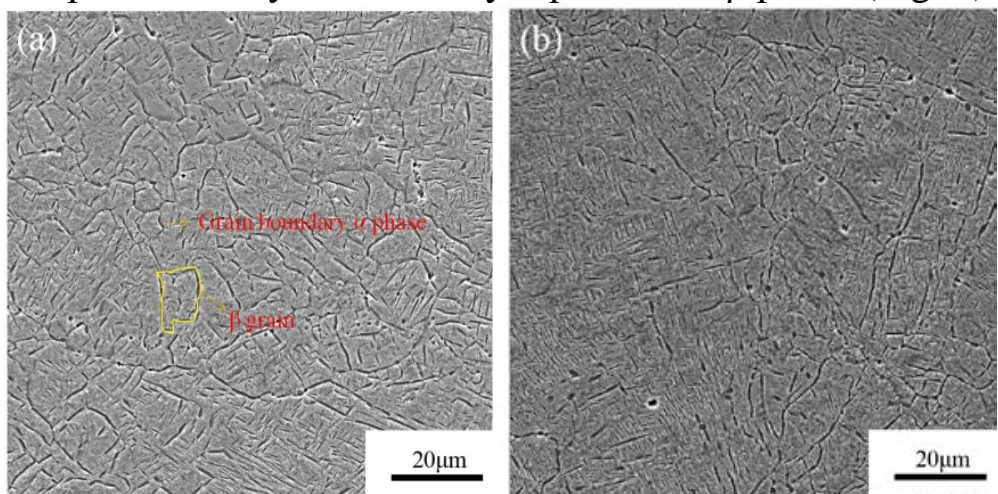

Fig. 4 SEM morphology of TB17 titanium alloy solution heat-treated at $825^{\circ} \mathrm{C}$ and aged for $8 \mathrm{~h}\left(\mathrm{a} .530^{\circ} \mathrm{C}\right.$; b. $\left.620^{\circ} \mathrm{C}\right)$

The microstructure of TB17 titanium alloy along the transversal section after $\alpha / \beta$ solution treated at $810^{\circ} \mathrm{C}$ plus aging at $530^{\circ} \mathrm{C}$ and $620^{\circ} \mathrm{C}$ are shown in Fig. 4 . For the $\beta$ titanium alloys, the primary $\alpha$ phase limit the recrystallization and growth of $\beta$ phase grains. As Fig. 4 showns the primary $\alpha$ phase distributes at $\beta$ phase grain boundary with the $\beta$ grain size is only about $15 \mu \mathrm{m}$ both aging at $530^{\circ} \mathrm{C}$ and $620^{\circ} \mathrm{C}$. It means that the primary $\alpha$ phase has a distinctly pinning effect on growth of $\beta$ grain during solution at $820^{\circ} \mathrm{C}$.
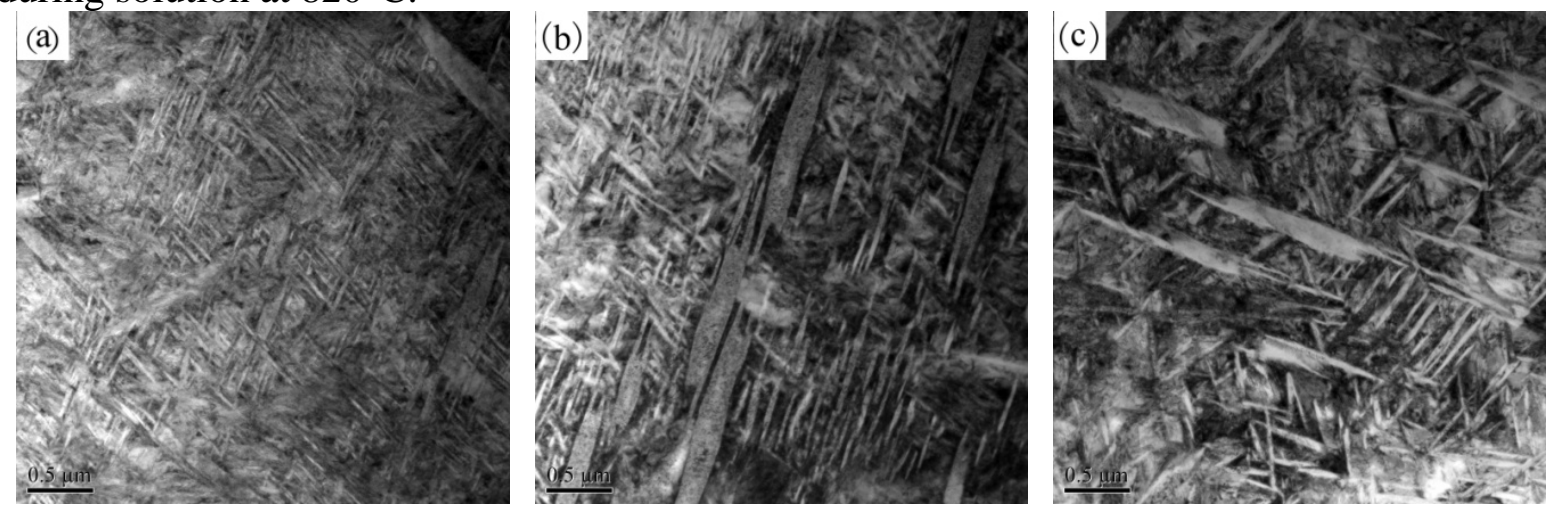

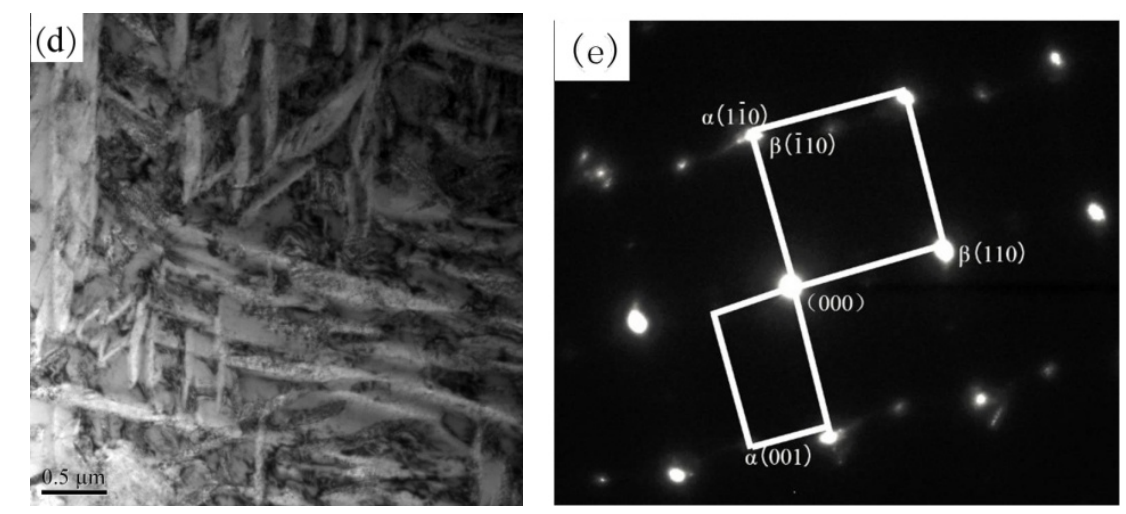

Fig. 5 TEM morphology of TB17 titanium alloy solution heat-treated at $825^{\circ} \mathrm{C}$ and aged for $8 \mathrm{~h}\left(\mathrm{a} .530^{\circ} \mathrm{C}\right.$; b. $550^{\circ} \mathrm{C} ;$ c. $570^{\circ} \mathrm{C}$; d. $620^{\circ} \mathrm{C}$; e. $530^{\circ} \mathrm{C}$ )

Fig. 5 shows the TEM microstructure and corresponding electronic diffraction (ED) image of TB17 titanium alloy after the $\alpha / \beta$ solution treatment aging range from $530^{\circ} \mathrm{C}$ to $620^{\circ} \mathrm{C}$, respectively. The aging temperature has a great effect on the size of acicular $\alpha$ phase. During aging at $530{ }^{\circ} \mathrm{C}$, the size of acicular $\alpha$ precipitates in the $\beta$ matrix is about $0.25 \mu \mathrm{m}$ in length and $0.04 \mu \mathrm{m}$ in width, the microstructure is homogenous, and the aging temperature raise to $570^{\circ} \mathrm{C}$, the lamella of secondary $\alpha$ phase were not grew up obviously, while during aging at $620^{\circ} \mathrm{C}$, the inhomogeneous microstructure formed, and the secondary $\alpha$ phase is about $0.95 \mu \mathrm{m}$ in length and $0.125 \mu \mathrm{m}$ in width. Electronic diffraction image demonstrate that secondary $\alpha$ phase have Burgers relation with $\beta$ phase matrix (Fig. 5e).

\subsection{Mechanical Properties}

Fig.6 shows the variation of mechanical properties of TB17 titanium alloy at various aging temperature. Comprehensively, the TB17 titanium alloy has a quite excellent combination of strength and ductility at the aging temperature from $530^{\circ} \mathrm{C}$ to $620^{\circ} \mathrm{C}$. The strength level decrease from $1500 \mathrm{MPa}$ to $1250 \mathrm{MPa}$ and excellent ductility increase from $6.8 \%$ to $15.0 \%$ in elongation. The change of mechanical properties might be affected synthetically by primary $\alpha$ phase morphology, fraction and secondary $\alpha$ phase, and it will be discussed in chapter 4 .

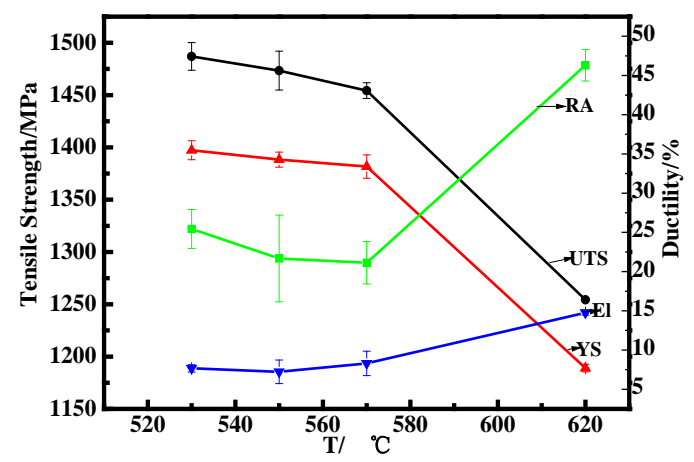

Fig. 6 The effect of aging temperature on the tensile properties at room temperature of TB17 titanium alloy

Fig.7 shows the nominal engineering stress-strain curves of TB17 titanium alloy at different aging temperature. At both aging temperature of $530^{\circ} \mathrm{C}$ and $620^{\circ} \mathrm{C}$, the characteristics of stress-strain curves is similar and can be divided into three stages, i.e. plastic deformation stage (stage I), yield stage (stage II), and fracture stage (stage III). The stress-strain curve at aging temperature of $620^{\circ} \mathrm{C}$ has longer yield stage and fracture stage comparing with that of $530{ }^{\circ} \mathrm{C}$. The alloy presents higher ultimate tensile strength at aging temperature of $530{ }^{\circ} \mathrm{C}$ comparing to that of $620^{\circ} \mathrm{C}$. 


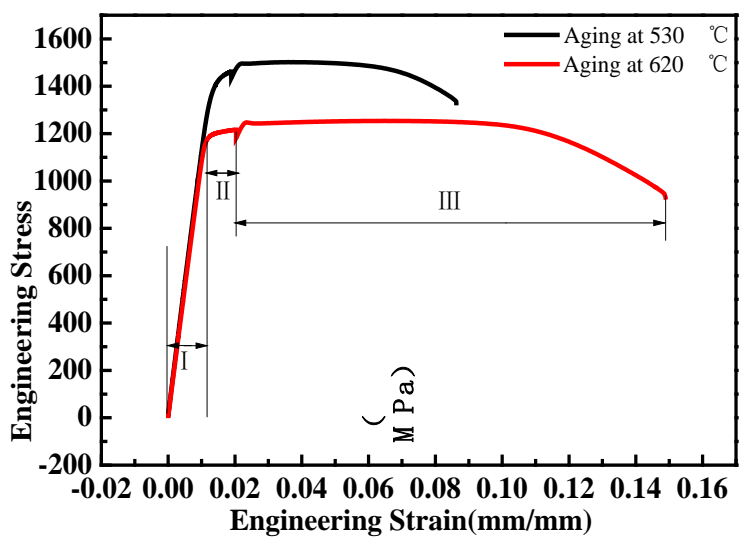

Fig.7 Nominal engineering stress-strain curve of TB17 titanium alloy at different aging temperature

\subsection{Fracture Analysis}

Fig.8 shows the room temperature fracture microstructure with different aging temperature. At aging temperature of $530^{\circ} \mathrm{C}$, the fracture contains large amounts of dimple and tear ridge (Fig. 8a), which acts as pale-type and tear-type fracture, and presents the characteristics of both quasi-cleavage and ductile fracture, and also the crack path is straight as shown in Fig. 10a. With the aging temperature raising to $620^{\circ} \mathrm{C}$, fracture morphology contains deep dimples (Fig.8b), with lots of core particles at the bottom of the deep dimple, which has the characteristics of ductile fracture, and the crack path is zigzag.
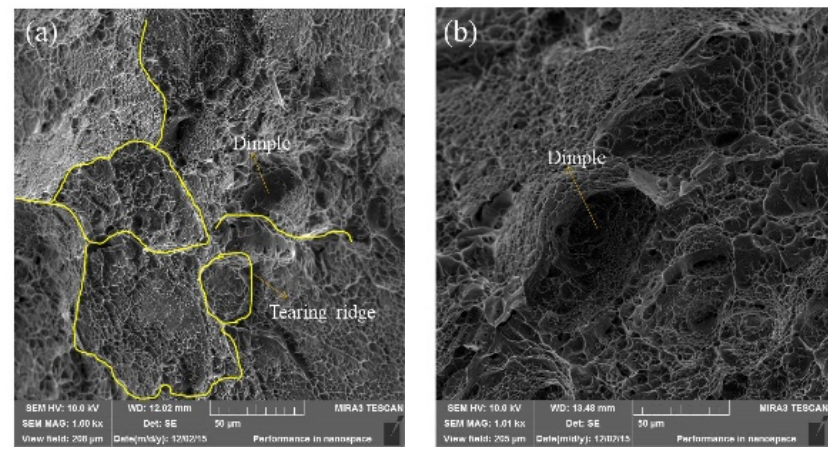

Fig.8 SEM micrographs showing fracture surface of TB17 titanium alloy at different aging temperature $\left(\mathrm{a} .530^{\circ} \mathrm{C} ; \mathrm{b} .620^{\circ} \mathrm{C}\right)$
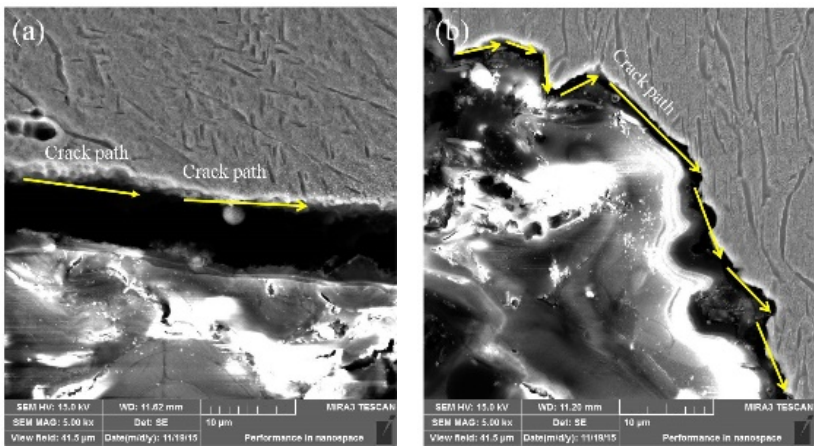

Fig.9 SEM micrographs showing crack path profile of TB17 titanium alloy at different aging temperature $\left(\mathrm{a} .530^{\circ} \mathrm{C} ;\right.$ b. $\left.620^{\circ} \mathrm{C}\right)$

\section{Discussion}

As Fig.3 shows the microstructure of TB17 titanium alloy during aging temperature ranged from 
$530^{\circ} \mathrm{C}$ to $620^{\circ} \mathrm{C}$ only consisted by $\alpha$ phase and $\beta$ phase, thus, the change of mechanical properties mainly caused by lamella secondary $\alpha$ phase parameter. There are two main processes of metastable $\beta$ phase titanium alloys precipitation, nuclear and grow up [11]. Aging at lower temperature, there are much more nucleation for higher driving force but lower atomic diffusion rates, thus fine and uniform secondary $\alpha$ phase formed. Aging temperature raised from $530^{\circ} \mathrm{C}$ to $570^{\circ} \mathrm{C}$, the lamella of secondary $\alpha$ phase grew up from $40 \mathrm{~nm}$ to $55 \mathrm{~nm}$ with the ultimate tensile strength decreased $50 \mathrm{MPa}$ while the elongation without obvious changes. However, aging at higher temperature, the lower driving force and higher atomic diffusion rates dominate the precipitate process, the coarse and non-uniform secondary $\alpha$ phase formed. During aging temperature raised from $570^{\circ} \mathrm{C}$ to $620^{\circ} \mathrm{C}$, the lamella of secondary $\alpha$ phase coarsen from $55 \mathrm{~nm}$ to $125 \mathrm{~nm}$ with the ultimate tensile strength decreased about 250MPa and elongation increased about 7\%.

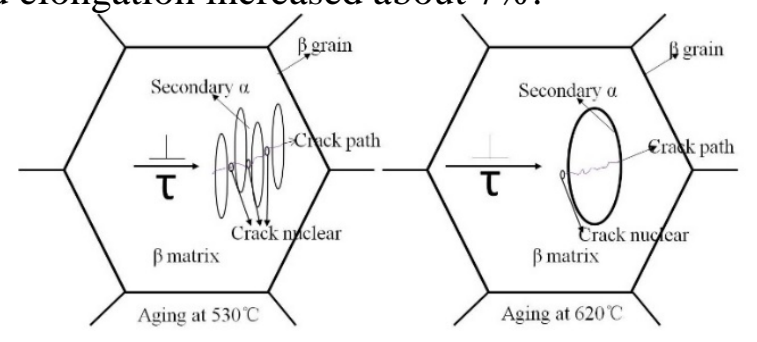

Fig.10 The schematic diagram of crack propagation of TB17 titanium aooly

The lamella of secondary $\alpha$ phase have significant effect on fracture behavior of TB17 titanium alloy. Generally, the interfacial energy is weaken than that of $\alpha$ or $\beta$ matrix, the $\alpha / \beta$ phase interface act as the potential site of crack under static stress. During aging at $530^{\circ} \mathrm{C}$, the fine and uniform increased much $\alpha / \beta$ phase interface which provide more site of nucleation and the stress concentration dispersed, thus the much energy were absorbed during the micro-cracks nucleation process and delay the plastic deformation zone, the higher ultimate tensile strength achieved[12-13]. Continue to load, the core of micro- crack expand and the yield area formed in front of the crack tip. The micro plastic zone formed during this stage[14]. As Fig. 10 shows if crack cross the fine and uniform secondary $\alpha$ phase, the straight and crack path formed. Some crack cannot pass through part of secondary $\alpha$ phase which have lower orientation factor instead expand along with cleavage plane, thus the cleavage edge formed(Fig.8a). During aging at $620^{\circ} \mathrm{C}$, the coarse and non-uniform secondary $\alpha$ phase intensively impede the motion of dislocation. The stress concentration at $\alpha / \beta$ phase interface lead to the TB17 titanium alloy enter the yield stage much more early (Fig. 6). During this stage the dislocation easier slip in $\beta$ phase for body-centered cubic (bcc) lattice structure and longer effective expand distance[15-16], thus the deeper dimple formed and the crack path more zigzag (Fig.10b).

\section{Conclusions}

1. TB17 titanium alloy has a great potential as aerospace structure material with a strength above $1500 \mathrm{MPa}$ and good strength-plasticity match (elongation 6.8\%) after solution and aging heat treatment.

2. The aging temperature of TB17 titanium alloy has a great influence on secondary $\alpha$ phase thickness, for eample, after $530^{\circ} \mathrm{C}$ aging, the thickness of lamellar of secondary $\alpha$ phase is $40 \mathrm{~nm}$, while aging temperature rises to $620^{\circ} \mathrm{C}$, lamellar $\alpha$ phase coarse to the thickness of $125 \mathrm{~nm}$.

3. There are two frcture mechanisms of TB17 titanium alloy for various secondary $\alpha$ phase morphology: fine and uniform secondary $\alpha$ phase contributes to quasi-cleavage fracture, while the course and nou-uniform $\alpha$ phase leads to the ductile fracture.

\section{References}

[1] Boyer RR. Titanium for aerospace Rationale and applications. Adv Perform Mater 1995; 2:349-68. 
[2] Machado A R, Wallbank J. Machining of titanium and its alloys - a review[J]. Proceedings of the Institution of Mechanical Engineers, Part B: Journal of Engineering Manufacture, 1990, 204(1): 53-60.

[3] Bania PJ. Beta titanium alloys and their role in the titanium industry. JOM 1994;46: 16-9.

[4] Guoqiang S, Zhishou Z, Hui C, et al. Development of ultrahigh strength titanium alloy[J]. Chinese Journal of Rare Metals, 2011, 35(2): 286-291.

[5] Srinivasu G, Natraj Y. Bhattacharjee A, Nandy TK, Nageswara Rao GVS. Tensile and fracture toughness of high strength $\beta$ Titanium. alloy $\mathrm{Ti}-10 \mathrm{~V}-2 \mathrm{Fe}-3 \mathrm{Al}$ as a function of rolling and solution treatment temperatures. Mater Des 2013,47: 323-330.

[6] Boyer RR. Titanium for aerospace Rationale and applications. Adv Perform Mater 1995;2: 349-68.

[7] Duerig T W, Williams JC.Overview: microstructure and properties of beta titanium alloys. In:Boyer R R, Rosenberg HW,editors. Beta titanium alloys in the 1980's. Altanta (GA)[J]:The Mteallurgical Society of AIME.1983: 19.

[8] Jackson M, Dashwood R J, Christodoulou L, et al. Application of novel technique to examine thermomechanical processing of near $\beta$ alloy Ti-10V-2Fe-3Al[J]. Materials science and technology, 2000, 16(11-12): 1437-1444.

[9] Ahmed M, Savvakin D G, Ivasishin O M, et al. The effect of cooling rates on the microstructure and mechanical properties of thermo-mechanically processed $\mathrm{Ti}-\mathrm{Al}-\mathrm{Mo}-\mathrm{V}-\mathrm{Cr}-\mathrm{Fe}$ alloys[J]. Materials Science and Engineering: A, 2013, 576: 167-177.

[10] N.G. Jones, R.J. Dashwood b, M. Jackson, D. Dye , $\beta$ Phase decomposition in Ti-5Al-5Mo-5V-3Cr. Acta. Materialia 57 (2009) 3830-3839.

[11] Allen P G, Bania P J. The Effect of Residual Work on the Aging Response of Beta Alloy. In: Weiss I eds. Advances in the Science and Technology: TMS,1996: 233-240.

[12]Ivasishin.O.M. Markovsky.P.E Aging response of coarse- and fine-grained titanium alloy[J]. Materials science and engineering.A.2005 (405):296.

[13] Lütjering G. Influence of processing on microstructure and mechanical properties of $(\alpha+\beta)$ titanium alloys. Mater Sci Eng A 1998,243: 32-45.

[14] J.K.Fan. J.S. Li. H.C.Kou, K. Hua, B.Tang. The interrelationship of fracture toughness and microstructure in a new near $\beta$ titanium alloy $\mathrm{Ti}-7 \mathrm{Mo}-3 \mathrm{Nb}-3 \mathrm{Cr}-3 \mathrm{Al}$. Materials Characterization 96 (2014) 93-99

[15] Yu Yongning. Principles of metallography. Metallurgical Industtry Press.2013:621-623

[16] Hamajima T, Lütjering G, Weissmann S. Importance of slip mode for dispersion-hardened b-titanium alloys. Metall Mater Trans B 1973,4: 847-56. 